\title{
Institucionalização da educação no Sul de Mato Grosso. O Grupo Escolar de Batayporã (1955-1974)
}

\author{
Institutionalization of education in the South of Mato Grosso. \\ The School Group of Batayporã (1955-1974) \\ Institucionalización de la educación en el Sur de Mato Grosso. \\ El Grupo Escolar de Batayporã (1955-1974)
}

Thierry Rojas Bobadilha

Rede Municipal de Ensino de Corumbá (Brasil)

http://lattes.cnpq.br/5791144273062980

https://orcid.org/0000-0001-7722-2777

thierryrojas@outlook.com

Rosemeire de Lourdes Monteiro Ziliani

Universidade Federal da Grande Dourados (Brasil)

http://lattes.cnpq.br/3469398097820732

https://orcid.org/0000-0002-9773-2632

rosemeireziliani@ufgd.edu.br

\section{Resumo}

O artigo socializa resultados de pesquisa concluída, realizada em Curso de Pós-Graduação em Educação, referente à educação primária oferecida no Grupo Escolar de Batayporã, sul do antigo Mato Grosso, que descreveu e analisou os principais elementos que permitiram seu aparecimento e funcionamento em um lugar específico e momento histórico datado. $\mathrm{O}$ recorte temporal da pesquisa foi o período de 1955 a 1974. Foram utilizadas noções inscritas na perspectiva foucaultiana, produções nacionais sobre instituições escolares e fontes escritas, imagéticas e orais. A escola, criada em 1955, constituiu um elemento material do dispositivo de institucionalização da educação na cidade, que, no momento da criação, não havia adquirido sua emancipação administrativa. Conclui-se que o seu aparecimento e funcionamento inicial favoreceram ou foram condições para a fixação de migrantes no projeto de colonização, como também a inscreveram nos discursos sobre a educação em circulação no Brasil naquele período histórico.

Palavras-chave: Projeto de colonização. Instituições escolares. Educação primária. 


\begin{abstract}
This paper focuses on the socialization aspects related to primary education offered at the Batayporã School Group, south of old Mato Grosso. The completed research for a postgraduate program in Education was carried out with the purpose of describing and analyzing the main elements that allowed the emergence and functioning of the school in a specific village within a historical moment between 1955 and 1974. Foucault's concepts and notions, national productions on school institutions, and, written, imagery and oral sources were used in this work. The school, created in 1955, constituted a material element of the institutionalization of education device in the village, which, at the time of its creation had not achieved its administrative emancipation. It was concluded that its emergence and initial functioning favored or offered conditions for the establishment of migrants in the colonization project, as well as inscribed the school in discourses in education circulating in Brazil in that historical moment.
\end{abstract}

Keywords: Colonization project. School institutions. Primary education.

\title{
Resumen
}

El artículo socializa los resultados de investigación completada, realizada en curso de postgrado en educación, referente a la educación primaria ofrecida en el Grupo Escolar de Batayporã, sur del antiguo Mato Grosso, que describió y analizó los principales elementos que permitieron su aparición y funcionamiento en un marco específico y momento histórico fechado. El recorte temporal de la investigación fue el período de 1955 a 1974. La investigación utilizó nociones inscritas en la perspectiva foucaultiana, producciones nacionales sobre instituciones escolares y fuentes escritas, imágenes y orales. La escuela, creada en 1955, se constituyó como elemento material del dispositivo de institucionalización de la educación en la ciudad, que en el momento de la creación no había adquirido su emancipación administrativa. Se concluyó que su aparición y funcionamiento inicial favorecieron o fueron condiciones para la fijación de migrantes en el proyecto de colonización, como también la inscribieron en los discursos sobre la educación en circulación en Brasil en aquel período histórico.

Palabras clave: Proyecto de colonización. Instituciones escolares. Educación primaria. 


\section{Introdução}

O artigo socializa resultados conclusivos de pesquisa desenvolvida em Programa de Pós-Graduação em Educação ${ }^{1}$, sobre a institucionalização da educação que se iniciou em 1955 , no Vale do Ivinhema, no distrito de Batayporã (fundado em 1953) ${ }^{2}$, no sul do antigo Mato Grosso $^{3}$. A pesquisa inscreve-se no campo da história das instituições escolares e buscou conhecer as características singulares do aparecimento e do funcionamento da escolarização em uma localidade e instituição específica, que não haviam sido estudadas.

Como recorte temporal foi definido o período de 1955 a 1974. A data inicial marcou o começo do funcionamento da instituição escolar, com sua criação oficial como Escola Rural Mista, transformada no mesmo ano em Grupo Escolar. O limite final, em 1974, deveu-se ao momento em que Grupo foi integrado ao Ginásio Estadual de Batayporã (criado em 1969), passando as duas instituições a funcionar com nova estrutura e denominação: Escola Estadual de $1^{\circ}$ Grau "Jan Antonin Bata", inserida na Rede Estadual de Educação e em conformidade com a Lei $\mathrm{n}^{\circ}$ 5.692, de 11 de agosto de 1971 (BRASIL, 1971).

A preocupação com a educação escolar, em questão na pesquisa, dirigiu-se para a relação entre o projeto de colonização e o aparecimento da instituição e para algumas das práticas que em seu interior se desenrolaram e lhe permitiram uma existência singular.

Alguns conceitos foucaultianos constituíram ferramentas analíticas e essa adoção implicou considerar os escritos sobre a escola e os ditos dos sujeitos como narrativas do nosso tempo e que contribuem para problematizá-lo. Assumir um diálogo com essas análises tem várias implicações, entre as quais se destacaram para a pesquisa ora socializada: a recusa da busca de uma origem e de uma noção de poder como algo que se detém e que emanaria de instituições como o Estado.

O poder foi concebido como relações de forças, que se exerce em diferentes espaçostempos sociais. Pode assumir formas palpáveis, pois se distribui na sociedade, materializa-se em instituições, em punições, em dominações; alcança o sujeito e invade o cotidiano, controlando os corpos e as mentes. Dialogando com Foucault (2004, p. 161), pode-se explicitar que o poder não deve ser pensado somente como algo negativo, ao contrário, ele é produtivo: "[...] o poder produz; ele produz realidade; produz campos de objetos e rituais da verdade. $\mathrm{O}$ indivíduo e o conhecimento que dele se pode ter se originam nessa produção".

Nesses termos, a noção de dispositivo foi tomada como uma rede de poder-saber que se delineia pelo conjunto complexo e heterogêneo de práticas discursivas e não discursivas (como a instituição escolar) e que se articula às demais estruturas sociais, econômicas e políticas. Desse modo, pode-se afirmar que a educação participa da rede que conforma o dispositivo; é um dos seus elementos. O dispositivo é um mecanismo com a capacidade de orientar, controlar, intervir nas condutas e no que as pessoas expressam. Esses conceitos e outros, tomados de empréstimo aos estudos foucaultianos, permitem afirmar o processo de institucionalização e a própria escolarização como dispositivos e a escola como sua parte visível.

As fontes documentais e eleitas para a pesquisa foram localizadas no arquivo da Escola Estadual "Jan Antonin Bata" e no Centro de Memória "Jindrich Trachta", ambas as instituições

\footnotetext{
${ }^{1}$ A pesquisa contou com o apoio da Coordenação de Aperfeiçoamento de Pessoal de Nível Superior (CAPES), da Fundação de Apoio ao Desenvolvimento do Ensino, Ciência e Tecnologia do Estado de Mato Grosso do Sul (FUNDECT/MS) e da Universidade Federal da Grande Dourados (UFGD).

${ }^{2}$ Ziliani (2010) explica que o nome Batayporã é uma associação da língua guarani antecedido do sobrenome Bata (proprietário da colonizadora). Bata, $y=$ água, porã = boa, que significa "água boa do Bata", em tradução livre. Esclarecemos que em 2007 (PREFEITURA MUNICIPAL, 2007), o nome da cidade passou a ser escrito com "y". Neste artigo usamos Batayporã, exceto nas citações diretas das fontes do período do recorte.

${ }^{3}$ O Estado de Mato Grosso foi dividido em 1977, com a criação do Estado de Mato Grosso do Sul, conforme a Lei Complementar n 31, de 11 de outubro de 1977 (BRASIL, 1977). Atualmente, Batayporã é um município do Estado de Mato Grosso do Sul.
} 
localizadas no município de Batayporã ${ }^{4}$, como livros de chamada, relatórios, livro de aparelhamento escolar e fotografias. Foram ainda consideradas como fontes algumas narrativas de sujeitos que contribuíram especialmente na feitura e no funcionamento da instituição escolar nas décadas iniciais. ${ }^{5}$ As fontes - documentais, imagéticas e orais - não foram hierarquizadas, sendo tomadas como produtoras da realidade e dos sujeitos de que tratam.

As narrativas dos sujeitos enfatizadas não foram concebidas como "expressão de individualidades", como algo homogêneo ou como "unidade subjetiva". Tratou-se de entender a memória como "[...] composta de fragmentos de múltiplas vivências e experiências ao nível individual e coletivo" (ALBUQUERQUE JÚNIOR, 2007, p. 200), enfim, tomaramse as memórias como multiplicidades; como posicionamentos dos sujeitos, sempre constituídos na relação com os outros. ${ }^{6}$

Historicizar essas memórias individuais e coletivas é, de certa maneira, interpretá-las em suas múltiplas significações; propor uma elaboração do passado, entre as possíveis, conforme conceitos adotados como operadores de análise.

Para conhecimento da arquitetura e dos modos de organização das edificações, foram utilizadas fotografias de época, que, para Lima e Carvalho (2009, p. 36), podem significar um "recorte casual que escapou aos textos, [e] ofereceria o acesso ao ambiente e aos tipos humanos que frequentavam o local". As fotografias encontradas no acervo do Centro de Memória "Jindrich Trachta" registram cenas das salas de aula e do cotidiano escolar, das edificações, de festas cívicas, encontros com autoridades, características do lugarejo, de estabelecimentos comerciais, de automóveis e carros de boi, da extração de madeira e de famílias residentes na cidade.

Nas imagens que retratam a Escola Rural Mista, depois denominada Grupo Escolar de Batayporã, pode-se observar, pelo menos em parte, as pessoas envolvidas e as atividades valorizadas, além de outros aspectos do cotidiano escolar e da cidade. As fotografias disponíveis nos arquivos consultados parecem ter tido a função de "registrar eventos e situações importantes para a preservação da memória da instituição" (SOUZA, 2001, p. 80) e da cidade, nas primeiras décadas de seu funcionamento.

Seguindo o referencial teórico-metodológico adotado, pode-se ressaltar que a pesquisa sobre a Instituição não pretendeu buscar sua origem cristalina, algo que teria surgido sem embates, relações de forças, movimentos de munícipes e outros. Tratou-se de tentar mapear seus começos dispersos, inscritos em discursos e práticas diversos, dos quais a instituição escolar é apenas um dos efeitos.

Para uma aproximação do objetivo, o texto foi organizado em duas partes. Na primeira, o trabalho enfocou questões relativas à fundação da Colônia e, na segunda, foram descritas e analisadas as condições de criação da Escola e os aspectos pinçados de seu funcionamento nas duas primeiras décadas.

\section{Discursos sobre colonização e a constituição da cidade de Batayporã}

O objetivo nesta parte foi abordar os aspectos centrais do dispositivo de nacionalidade e a noção de progresso que lhe corresponde, em voga na primeira metade do século XX. Foram apontados elementos referentes ao processo de colonização da região do Vale do Ivinhema até a criação da cidade de Batayporã.

${ }^{4} \mathrm{O}$ Centro de Memória foi criado por descendentes de imigrantes tchecoslovacos, que atuaram na Companhia colonizadora, denominada Companhia Viação São Paulo Mato Grosso (CVSPMT), para manter viva a memória da colonização na região. Esses imigrantes vieram para o Brasil nos anos de 1940, para atuar na recém-criada Colônia de Samambaia, que ainda na década de 1950 viria a se chamar "Batayporã".

${ }^{5}$ As fontes orais foram produzidas por meio de entrevistas, gravadas e transcritas, realizadas na cidade de Batayporã, entre 2014 e 2015, e contaram com narrativas de cinco sujeitos. Esclarecemos ainda que o nome dado ao sujeito neste artigo é fictício.

${ }^{6}$ Texto sobre as memórias dos sujeitos da escola foi apresentado em evento da área da educação do CentroOeste, em 2015. 
No dispositivo inscreveu-se o processo de colonização ocorrido nos anos de 1940 e 1950, no sul do antigo Mato Grosso. Considerar esse processo implicou uma aproximação dos discursos sobre a Companhia Viação São Paulo Mato Grosso (CVSPMT) e alguns dos projetos por ela realizados, além do aparecimento da Colônia de Samambaia, posteriormente distrito de Batayporã, como dos colonos que nela se fixaram.

Desde os fins do século XIX no Brasil", com o objetivo de fazer uma "história oficial da nação", foram criadas instituições como o Instituto Histórico e Geográfico Brasileiro (IHGB), em 1839, visando a demarcar os espaços do território brasileiro. Galetti (2012, p. 33, grifo da autora) afirma que, no país, "[...] uma parcela significativa de intelectuais e dirigentes políticos, sobretudo a partir da segunda metade do século XIX, passaria a perceber os sertões da pátria - ou simplesmente o sertão - como o outro geográfico da Nação”. Essas e outras proposições circularam ao longo da primeira metade do século XX, sendo usadas para justificar a colonização de terras consideradas "não conhecidas" do território brasileiro.

Os anos de 1930 a 1945 foi o período em que Getúlio Vargas governou o país. Em 1937, iniciava-se o Estado Novo e, no ano seguinte, foi lançada a campanha denominada "Marcha para o Oeste", que almejava unir a nação na conquista dos lugares inexplorados. Foi nesse contexto

que Mato Grosso se tornou objeto das atenções nacionais. Perpassada de uma série de conteúdos místicos e construções imaginárias, a campanha possibilitava apresentar uma imagem homogênea de nação e do Estado superador dos conflitos sociais. (GUILLEN, 1996, p. 39).

Porém, segundo o autor, a Marcha ocultava que o Oeste se encontrava permeado por relações de poder complexas, como a presença das companhias de extração de erva-mate, as usinas de açúcar, as fazendas de gado e outras propriedades de exploração no sul do Mato Grosso. Havia ainda uma acentuada preocupação com a identidade nacional, com a integração e unidade das áreas de fronteira e os chamados "sertões".

Desde a primeira metade da década de 1930, Getúlio Vargas dera início à valorização do campo e do homem da pequena propriedade, iniciando as políticas de colonização, que propunham uma assistência inicial aos colonos, que abrangiam o trabalho, a educação primária aos seus filhos e a saúde, para se tornarem independentes. Em Mato Grosso, esse "cerco" se deu principalmente pela empresa Matte Laranjeira, que dominava boa parte do sul do Estado (GUILLEN, 1996) ${ }^{8}$.

Esse "esquadrinhamento dos corpos" era necessário para controlar os colonos e civilizálos para a convivência social. O processo de disciplinamento pretendia fazer dos colonos pessoas mais hábeis para o trabalho e para o sucesso da política de colonização, orientando-os para as novas formas de se portar em sociedade. Segundo Guillen (1996, p. 43), o Estado Novo, ao dar visibilidade ao sul do antigo MT "[...] com a Marcha, tentava imprimir uma imagem de futuro: finalmente integrada ao corpo da Nação, a região da fronteira alcançaria o progresso e o desenvolvimento que parte do país desfrutava".

Para a efetivação dessa estratégia, que visava principalmente à colonização de terras e à povoação dos "sertões vazios e inóspitos", contou-se com a atuação de empresas e de companhias colonizadoras objetivando, entre outras questões, o povoamento das terras

\footnotetext{
${ }^{7}$ Desde o século XIX no Brasil, discursos em circulação defendiam a noção de evolução, que permitia reconhecer as diferenças e determinar a inferioridade da parcela indígena, afrodescendente e ex-escravo, contrapondo-se aos descendentes europeus, brancos e civilizados. Conforme Schwarcz (2014), a higienização e a educação do povo constituíam ferramentas para a correção e o aperfeiçoamento do homem.

${ }^{8}$ A exploração da erva-mate teve início na década de 1880 , após a demarcação da linha fronteiriça BrasilParaguai, sendo o brasileiro Thomaz Laranjeira considerado sócio-fundador da Companhia Matte Larangeira, que explorava os ervais da região sul do antigo Mato Grosso. Sobre as atividades da Companhia foram realizados estudos acadêmico-científicos, além de publicações institucionais.
} 
devolutas $^{9}$. Entre essas empresas esteve a CVSPMT, envolvida na atividade de colonização, inclusive de uma parte do antigo sul do Mato Grosso.

A CVSPMT foi fundada em 1908, em substituição à firma Diederichsen \& Tibiriçá. ${ }^{10}$ Em 1941, passa a ser propriedade do tchecoslovaco Jan Antonin Bata (ZILIANI, 2010). ${ }^{11}$ Tinha como finalidade atividades industriais e comerciais e de exploração de terras devolutas no Estado de São Paulo e Mato Grosso, visando a criar colônias e vender terras devolutas. ${ }^{12}$ No Estado do Mato Grosso, as colônias que dariam origem às cidades de Bataguassu e de Batayporã foram fundadas, respectivamente, em 1946 e 1953. De acordo com o autor, a Companhia fez circular em 1942, por meio de seu impresso, o Jornal Ordem e Progresso (2010), a oportunidade de compra de terras na região do Vale do Ivinhema, sul do antigo Mato Grosso. O impresso utilizou o discurso em circulação de que havia "terras boas" a serem exploradas. As publicações desse Jornal serviam bem ao ideal do Estado Novo e de suas estratégias de colonização: "[...] nosso trabalho e da nossa capacidade que são unicamente dirigidos no sentido de satisfazer os nossos desejos de servir, sempre na frente, o desenvolvimento do País" (JORNAL ORDEM E PROGRESSO, 2010, p. 191).

Em 1953, o imigrante tchecoslovaco Vladimir Kubik, funcionário da CVSPMT, foi encarregado de selecionar um lugar adequado para iniciar a venda de lotes de terras, especialmente para a criação de gado e a extração de madeira, dando início ao núcleo da Colônia. Em 1954, surge um novo personagem na colônia de Batayporã, o também tchecoslovaco Jindrich Trachta ${ }^{13}$, que ficou responsável pela venda das terras, atendimento aos colonos e proprietários das "novas" terras e de elementos de infraestrutura, além de atividades fabris, agrícolas e de criação de animais.

Ressalta-se que a regulamentação de Batayporã como distrito ocorreu no mesmo ano da criação da Colônia, em 1953, momento em que Bataguassu ${ }^{14}$ alcançou sua emancipação político-administrativa. O distrito possuía no final da década de 1950, além da fazenda sede da Companhia, prédios de serrarias, olarias, fábricas de amido, hotel, igreja, casas residenciais, pequenos comércios e uma escola.

No Livro de Matrícula, Frequência Diária e Aparelhamento Escolar (GRUPO ESCOLAR DE BATAYPORÃ, 2015b), da Escola Rural Mista de Batayporã, há registro do perfil dos pais dos alunos matriculados. Pode-se afirmar que as famílias de migrantes e de imigrantes que se instalaram na Colônia eram de origens bem diversas, como a nordestina, paulista, mato-grossense, paranaense, japonesa, portuguesa e espanhola, além dos tchecoslovacos que lá residiam, evidenciando o "caldeirão" cultural que a compôs. A função

\footnotetext{
${ }^{9}$ Terras devolutas são aquelas que não possuem um uso público, que não se encontram em domínio particular ou que são posses legitimadas pela Lei de Terras $n^{\circ}$ 601, de 1850 (BRAZIL, 1850).

${ }^{10} \mathrm{~A}$ firma Diederichsen \& Tibiriçá foi uma grande empresa de colonização da Alta Sorocabana. Seus principais acionistas e fundadores foram o médico e lavrador Arthur Diederichsen e o médico Francisco Tibiriçá. Em 1927, ela foi vendida a outro grupo de empresários alemães e, em 1941, foi comprada pelo tchecoslovaco Jan Antonin Bata.

${ }^{11}$ Segundo Ziliani (2010), Jan Bata possuía uma empresa de calçados nos Estados Unidos, na década de 1930, sendo perseguido por donos de outras empresas por ameaçar as vendas dos seus produtos. Em 1940 adquiriu a Companhia, apoiado pelos presidentes Getúlio Vargas e por Eurico Gaspar Dutra, recebendo naquele momento a cidadania brasileira.

${ }^{12}$ A Companhia tinha ainda como finalidade explorar a indústria de navegação no rio Paraná e afluentes, além das atividades de criação e corte de gado. A partir da década de 1940 ampliou suas atividades de criação de núcleos coloniais, sendo responsável por diversos projetos de colonização, fundando cidades no Estado de São Paulo, como também no sul do antigo Mato Grosso (ZILIANI, 2010).

${ }^{13}$ Jindrich Trachta foi trabalhar na Companhia e administrar empreendimentos na recém-criada Colônia, a convite de Jan Bata. Casou-se e constituiu família no Brasil. Sua casa, também escritório, era o local onde Bata se hospedava quando estava na Colônia. Nos anos de 2000 foi organizado no local o Centro de Memória "Jindrich Trachta", contemplando um acervo documental da família e da Companhia.

${ }^{14}$ Conforme dados do Instituto Brasileiro de Geografia e Estatística (IBGE) (1958, p. 89), na cidade de Bataguassu havia "[...] 9 escolas rurais no ano de 1955, 5 estabelecimentos de Ensino Primário no ano de 1956, somando 203 alunos, sendo um localizado no Distrito de Bataiporã”.
} 
principal que afirmavam exercer era a de lavradores, mas havia também motoristas, padeiros, domésticas, carpinteiros, sapateiros, policiais, barbeiros, comerciantes, açougueiros, juiz de paz, pensionistas, farmacêuticos e "donas de casa" (GRUPO ESCOLAR DE BATAYPORÃ, 2015b). Segundo as narrativas dos alunos entrevistados, seus pais plantavam café, milho, arroz, feijão-de-corda, além de criar galinhas e porcos. O pai de um deles trabalhava como administrador das terras da Companhia.

Esse documento traz ainda dados sobre religião, instrução e profissão dos colonos, pais dos alunos do período de 1957-1964, conforme declarados no ato das matrículas. Pode-se constatar que a maioria dos colonos era analfabeta, principalmente as mulheres que se dedicavam ao cuidado dos próprios lares ou trabalhando na casa de outras famílias, seguidos de alguns com ensino primário e outros poucos com o ensino secundário.

Esse retrato geral dos anos iniciais da Colônia, com a chegada de migrantes/imigrantes oriundos de diferentes regiões do país, crentes nos chamados da Companhia e nos discursos oficiais da época sobre "desenvolvimento" e "progresso" da nação, evidencia a funcionalidade das estratégias utilizadas.

\section{Educação no Brasil e no Estado}

O objetivo nesta parte foi o de retomar as linhas gerais da educação no país, visando a analisar a escolarização primária oferecida em Batayporã, no período de 1955 a 1974, materializada em uma instituição escolar, inicialmente denominada Escola Rural Mista de Batayporã e, em seguida, Grupo Escolar de Batayporã.

Desde o início do século XX, em especial, a educação da população constituía condição ao desenvolvimento da nação; enunciado que circulava em diferentes discursos. O analfabetismo da parte pobre da população era visto como um mal que inviabilizava a "civilização" e a "evolução" do país. Entendido como "[...] doença social, a falta de escolarização era a ideia força de uma razão clínica em processo permanente de apropriação por parte dos que consideravam o analfabetismo o pai de todos os males da nação" (FREITAS; BICCAS, 2009, p. 41).

Existiam no final do século XIX as chamadas escolas isoladas e as rurais ${ }^{15} \mathrm{em}$ funcionamento no país, paulatinamente substituídas por um "novo" modelo de escola denominada "Grupo Escolar", que surge inicialmente em São Paulo e no Rio de Janeiro. Ao longo das duas primeiras décadas do século XX, esse modelo de escola surge em vários outros Estados do país, inclusive em Mato Grosso uno. Foram criados com a expectativa de contribuir para o país desenvolver-se economicamente e apresentados como modelo de ruptura com o passado imperial: "[...] projetavam para o futuro, projetavam um futuro, em que na República, o povo, reconciliado com a nação, plasmaria uma pátria ordeira e progressista" (FARIA FILHO; VIDAL, 2000, p. 25). ${ }^{16}$

As chamadas Leis Orgânicas do Ensino (BRASIL, 1942-1946 apud IGNACIO, 2006), ${ }^{17}$ desse período, tiveram seus efeitos duas décadas depois de serem promulgadas, isto é, na segunda metade dos anos de 1950, momento em que a Escola estudada foi criada. Segundo Freitas e Biccas (2009, p. 115), trouxeram como novidades: a padronização do currículo nacional, o tipo de arquitetura escolar, os uniformes, a verificação da higiene dos estudantes e outros aspectos; além

\footnotetext{
${ }^{15}$ De acordo com Souza (1998, p. 51), nas primeiras décadas do século passado, as escolas isoladas rurais “"[...] sobreviveram à sombra dos grupos escolares nas cidades, nos bairros e no campo. Apesar de elas serem consideradas tão necessárias, os grupos foram mais beneficiados, e nelas continuou predominando a carência de tudo".

${ }^{16}$ Ainda que os grupos escolares tenham aparecido e se configurado com pretensão de serem a principal referência à escolarização das crianças, sua "pretendida hegemonia" não se efetivou. Eles deixaram de existir com a promulgação da Lei no 5.692/1971 (BRASIL, 1971).

17،“As chamadas 'Leis' Orgânicas ou Reforma Capanema [... são] um conjunto de Decretos-Lei elaborados por uma comissão de 'notáveis' presidida por Gustavo Capanema e outorgados pelos presidentes Getúlio Vargas durante o Estado Novo e José Linhares durante o governo provisório. [...]. Tiveram como objetivos, reformar e padronizar o sistema nacional de educação" (IGNÁCIO, 2006, p. 1, grifo do autor).
} 
de disseminar um "sentimento de patriotismo e da nacionalidade". Em 1951, foi aprovada a Lei Orgânica do Ensino Primário do Estado de Mato Grosso, Lei no 452 (MATO GROSSO, 2001), que regulamentou a oferta do ensino primário no Estado do Mato Grosso.

Acordos entre o Instituto Nacional de Estudos Pedagógicos (INEP) e o governo matogrossense possibilitou, segundo Brito (2001), a construção de 161 prédios na zona rural entre 1947 e 1953, e, nesse período, mais 23 estavam sendo construídos e 30 ainda não haviam sido iniciados.

A ocupação do Estado do Mato Grosso deu-se de forma mais intensa a partir da década de 1950, isso porque se intensificou a exportação de alimentos derivados da pecuária e agricultura para outros lugares do Brasil e do mundo, iniciativas colonizadoras no sul do Estado e a construção da malha ferroviária entre a cidade de Corumbá e a Bolívia. Com tais empreendimentos, a população aumentou na zona rural do Estado, o que fez com que as escolas rurais isoladas se multiplicassem pelo território estadual. Brito (2001) afirma que a administração pública reconheceu a importância dessas escolas rurais, investindo na melhoria do ensino no interior do Mato Grosso. A instituição escolar do distrito de Batayporã, implantada em 1955, fez parte dos dados levantados por essa autora.

A primeira Lei de Diretrizes e Bases da Educação (LDBE), Lei no 4.024 (BRASIL, $1961)^{18}$, foi promulgada em 1961, após treze anos de uma conturbada fabricação; definiu a estrutura da educação a ser ofertada no país, mas não deu a ênfase esperada pela sociedade civil organizada à escola pública.

Em 1962, o governador do Estado do Mato Grosso Fernando Corrêa da Costa regulamentou, por meio do Decreto $n^{\circ}$ 319/1962 (MATO GROSSO, 1962b), o Programa do Ensino Primário, que definiu as diretrizes gerais para o ensino de cada disciplina, estabelecendo também os deveres e direitos dos alunos e professores nas instituições de ensino primário do Estado.

Segundo o secretário de Educação, Cultura e Saúde Hermes Rodrigues de Alcântara, em Carta enviada ao governador em fevereiro de 1962, era necessário que:

O ensino primário em Mato Grosso sofresse substancial modificação em seu organismo. Para as Escolas Rurais e Isoladas Urbanas foram elaborados programas especiais, [...]. Os programas dos Grupos Escolares e das Escolas Reunidas, com significativos aperfeiçoamentos, fundamentam-se nos mais avançados sistemas de ensino do país (MATO GROSSO, 1962a, p. 4).

Essa legislação, em conexão com outros acontecimentos, compõe o mapa da educação daquele período, evidenciando que as prescrições, ou "concessões" nelas contidas, representavam, simultaneamente, os avanços e os limites em curso e que estavam longe de atender as demandas da população que já havia tomado para si o enunciado da educação escolar como imperativo ao desenvolvimento e como possibilidade de uma vida melhor.

Para o alcance do objetivo, no contato com as fontes documentais, imagéticas e orais, foram analisadas algumas de suas características: o processo de instalação da escola com as suas mudanças de nomenclatura e organização, as transformações na localização e nas edificações, a rotina escolar, o perfil dos professores, alunos e direção, o controle do comportamento dos alunos e o ensino moral e cívico.

\footnotetext{
${ }^{18}$ Durante o processo de elaboração da LDB em 1959, houve intensa campanha dos educadores ligados aos ideais reformistas, em defesa da escola pública, obrigatória, laica e gratuita e contra os defensores da educação privada ligados, sobretudo, às escolas católicas. Também participaram da campanha estudantes, trabalhadores organizados, escritores, com numerosas manifestações de pessoas empenhadas no movimento.
} 


\subsection{Criação e funcionamento inicial da Escola}

A preocupação com a educação escolar nesta parte dirigiu-se ao aparecimento da instituição, em especial, para práticas e discursos que lhe garantiram uma existência singular.

A institucionalização da educação para as crianças, na configuração sociopolítica denominada Batayporã, materializou-se com o aparecimento de uma instituição escolar, criada em 1955, denominada Escola Rural Mista de Batayporã ${ }^{19}$, posteriormente Grupo Escolar de Batayporã, criado pelo Decreto $n^{\circ}$ 2.066, de 4 de março de 1955 (MATO GROSSO, 2015). Observou-se que a criação oficial da Escola e mesmo sua transformação em Grupo Escolar ocorreram no mesmo ano e antes de o lugarejo emancipar-se administrativamente. Aspectos que podem evidenciar a urgência e importância que foi dada à educação naquele local.

A alfabetização das crianças também começou a funcionar antes mesmo de oficializada a criação da escola e de forma improvisada, por iniciativa da comunidade, em uma sala do único hotel existente no lugarejo. Contava no início com setenta alunos de diferentes idades, evidenciando a demanda existente e a adoção da educação escolar como "necessidade".

Com a denominação de Escola Rural Mista, a Instituição parece ter funcionado por pouco tempo, pois, em março de 1955, como já citado, foi criado o Grupo Escolar de Batayporã. Porém, a denominação Escola Rural Mista continuou aparecendo na escrituração até 1962. No Livro de Chamada de Alunos (ESCOLA RURAL MISTA, 2015), a denominação "Escola Rural Mista" aparece até o mês de abril e, desta data em diante, o termo Grupo Escolar aparece nos registros do mesmo documento, evidenciando que foi rápida a mudança na nomenclatura da Instituição.

Desde a Constituição Federal de 1946 (BRASIL, 1946), estava oficialmente assegurada a gratuidade do ensino primário e de os outros níveis de ensino que apresentassem falta de recursos, determinando que os governos federais, estaduais e municipais deveriam aplicar um percentual mínimo na educação. Em Batayporã foi observado que até parte da década de 1960 não houve investimentos para a escola por parte dos governos, exceto o pagamento de professores. Falta de apoio que não se restringia ao município em questão ou à instituição estudada.

Conforme relato da Primeira Professora do Grupo (ENTREVISTA, 2014) ${ }^{20}$, a CVSPMT ajudou na construção do prédio da Escola com a compra dos materiais permanentes. Nas narrativas dos demais entrevistados, observou-se a necessidade de evidenciar que a Escola tinha, desde seu começo, alguma relação com a Companhia, mas enfatizaram a participação decisiva da comunidade local. A ênfase à Companhia aparece, em especial, na narrativa do aluno Davi (2014), filho de funcionário da Companhia; com ele aparece uma indicação direta de valorização do apoio da empresa na construção e manutenção da Instituição, entretanto, o apoio parece ter sido restrito.

Pela importância dada à educação escolar já naquele momento histórico, pode-se afirmar um interesse da Companhia pela Instituição, tendo como condição a permanência das famílias e a efetivação do projeto de colonização em curso. Mas essa constatação não parece ter se materializado em investimentos, antes tal prática discursiva se efetivou à custa do esforço da "população" e essa parece ter sido de fato a estratégia.

Observou-se ainda que alguns documentos ${ }^{21}$ da escrituração escolar do primeiro ano de funcionamento da Instituição, como livros de chamada e de matrícula, eram impressos do Estado de São Paulo, sinalizando, além da pouca assistência governamental, a dificuldade de

\footnotetext{
${ }^{19}$ Não foi localizado o Decreto ou documento de criação da Escola Rural Mista, apenas indicações de que sua criação ocorreu naquele ano, em fotos disponíveis no Centro de Memória "Jindrich Trachta" e em narrativas.

${ }^{20}$ Denominação dada à primeira professora do Grupo entrevistada para a pesquisa.

${ }^{21}$ Documentos arquivados na Escola Estadual "Jan Antonin Bata", onde foram localizados registros em formulários de escrituração escolar do Estado de São Paulo dos anos de 1960, 1963 e de 1966. Além da proximidade geográfica, pode-se levantar a hipótese do contato entre a Companhia e o poder público paulista.
} 
acesso, dos que ali residiam e dos envolvidos com a educação, a capital Cuiabá, onde se localizava a administração estadual.

Pelas informações disponibilizadas, os livros, cartilhas, giz e outros materiais para a realização das aulas não eram disponibilizados pelo governo. Também não foram obtidos registros de recursos ou outro tipo de fornecimento de merenda para os alunos. Identificou-se ainda que, até a primeira metade dos anos de 1960, não existia uma caixa escolar como previsto desde o Regulamento da Instrução Pública Primária do Estado de Mato Grosso (MATO GROSSO, 1927).

Até a emancipação político-administrativa de Batayporã, não foram localizados comprovantes da participação do governo estadual na manutenção da instituição escolar, porém, nas narrativas, aparecem informações de que alguns pais de alunos, quando podiam, colaboravam com a doação de alimentos ou material escolar, como lápis, borracha e cadernos para alunos de baixa renda, que eram maioria. Além da Primeira Professora (2014), que afirmou comprar durante vários anos materiais como lápis, cadernos, borracha e até cartilha para os seus "alunos mais pobres", vindos do Estado de São Paulo, considerando as distâncias entre as cidades do então Mato Grosso.

Outro aspecto considerado na pesquisa foi a arquitetura, os edifícios, a localização da Escola na organização espacial da cidade e seu mobiliário, como a parte material de seu funcionamento (FRAGO; ESCOLANO, 2001).

A sede da Escola nos anos de seu funcionamento mudou de localização. Partindo da análise de fotografias disponíveis no Centro de Memória e narrativas dos sujeitos, foi possível concluir que ela iniciou seu funcionamento em 1955, em um quarto da única pensão existente na pequena cidade. Todos os alunos eram alfabetizados em um mesmo espaço físico. A Primeira Professora (2014) afirmou que chegou um momento em que aquele espaço, no hotel, se tornou "[...] muito pequeno e quente para tantas crianças".

Em 1957, foi construída a primeira edificação destinada para a Escola (Figura 1), feita de madeira, com duas salas pequenas, piso de terra batida e um banheiro fora do prédio. Estrutura singela que pouco se diferenciava de outras escolas rurais do período. Como evidencia Garnica (2011, p. 70), geralmente os estabelecimentos rurais “[...] funcionavam em cômodos de madeira, constituídos por apenas uma sala, sem a existência (ou com existência precária) de sanitários, cozinha e pátio”.

Figura 1. Prédio do Grupo Escolar de Batayporã, fundos (1957)

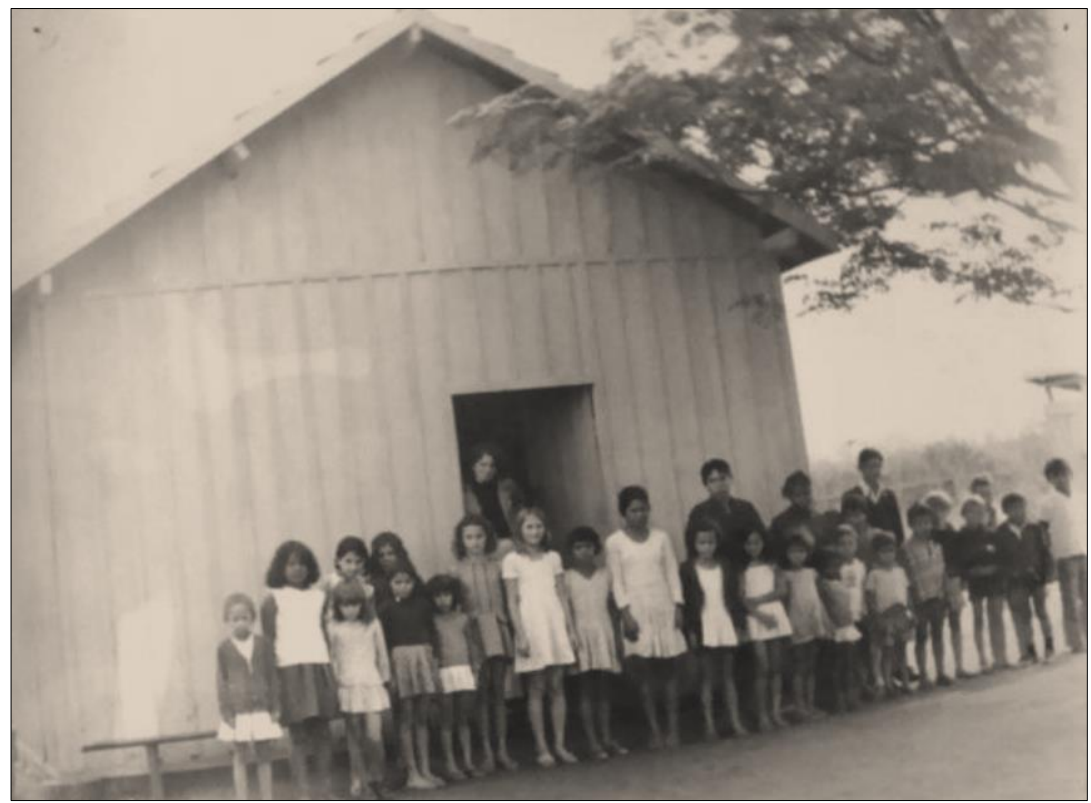

Fonte: Centro de Memória “Jindrich Trachta” (2015). 
Ainda assim, o cenário modificou-se com a construção dessa edificação, feita gratuitamente por dois carpinteiros portugueses que residiam na cidade. A construção não contou com o apoio financeiro do governo do Estado, mas com materiais cedidos pela Companhia e pela comunidade. Somente no final da década de 1960 é que o governo municipal construiu um prédio de alvenaria em outro espaço no mesmo terreno, para o funcionamento da Escola.

Com o apoio de Frago e Escolano (2001, p. 47), pode-se afirmar que a escola "[...] em suas diferentes concretizações, é um produto de cada tempo e suas formas construtivas são, além dos suportes da memória coletiva cultural, a expressão simbólica dos valores dominantes nas diferentes épocas". Nos poucos registros fotográficos localizados sobre o prédio de madeira é possível observar o mobiliário e a distribuição dos alunos no espaço, além de seus vestuários. Em uma das imagens há uma professora em pé na porta e seus 44 alunos, alguns com postura ereta e outros conversando, alguns descalços e outros, não. Observa-se, desse modo, que não havia exigência do uso de uniforme naquele momento.

Os alunos utilizavam, como carteira nas salas de aula, uma mesa fixada ao assento (banco), que acomodava, em geral, duas crianças. Em uma das fotos, três crianças acomodamse nas carteiras escolares, mas essa distribuição pode ter sido organizada apenas para que todos aparecessem na fotografia. Em outras imagens aparecem em duplas de meninos ou de meninas.

Segundo narrativa do aluno Davi (2014), somente em dias de exames sentavam-se juntos meninos e meninas, para que não houvesse a oportunidade de "conversas e cópias" durante a prova. Segundo narra, eram "dias de nervosismo", às vezes até chorava, pois tinha de compartilhar a mesa do exame com uma menina, visto que eles não tinham uma relação de "amizade" e "intimidade".

Dialogando com Frago e Escolano (2001), pode-se afirmar que a arquitetura escolar constitui um "programa", que controla os espaços, educa pela instauração de determinadas regras e imposição de hábitos, valores.

Mesmo os alunos sentando-se juntos durante as aulas, as práticas de ensinoaprendizagem não eram coletivas, mas individualizadas, pois o professor era o único responsável pelas atividades, "esquadrinhando-os" por meio de seus cadernos, de avaliações e notas, do controle do comportamento, em sua postura diante da sala de aula e todas as suas anotações escritas sobre cada aluno. Processo esse capaz de separar os corpos dos sujeitos, mesmo tão próximos. Para Foucault (2004, p. 123), nas instituições é importante

estabelecer as presenças e as ausências, saber onde e como encontrar os indivíduos, instaurar as comunicações úteis, interromper as outras, poder a cada instante vigiar o comportamento de cada um, aprecia-lo, sancioná-lo, medir as qualidades ou os méritos.

Cada uma e toda a arquitetura institucional contribuem para "compor" e "conformar" os indivíduos como sujeitos de tipos específicos (ROSE, 2001) e constitui elemento material do que denominamos "dispositivo de escolarização".

O Grupo Escolar de Batayporã não apresentava uma fachada grandiosa, escadarias, entradas para meninos e meninas, entre outros aspectos que foram pensados para esses edifícios construídos por todo o Brasil, do final do século XIX ao início do século XX, conforme apontam Buffa e Pinto (2002), Faria Filho e Vidal (2000) e Souza (1998). Segundo Faria Filho e Vidal (2000, p. 31-32):

Em lugar da suntuosidade exibida no início da República, a luta pela democratização da escola fazia-se sentir em prédios funcionalistas, tecnicamente projetados para uma educação rápida e eficiente, com lugares específicos para acolher maquinário, como mimeógrafo, e 
propiciar um controle do corpo docente através de mecanismos administrativos cada vez mais capilares, e nas soluções mais rústicas, que associavam ensino formal à casa do professor, nas zonas rurais.

Além da arquitetura, o "tempo escolar" foi inaugurado com a criação dos grupos escolares no país. Com eles, o tempo ganhou importância na organização do ensino. Faria Filho e Vidal (2000, p. 32) afirmam que " [...] o tempo escolar se associa às horas em que se permanece na escola, contabilizado em sinetas, recreios, cadernos, da mesma maneira que nos ponteiros do relógio". A divisão do ano letivo em aulas, períodos, dias, semestres, férias, também evidencia essa distribuição e o controle temporal.

Sem a obrigação de fornecimento de merenda por parte dos governos, estadual e municipal, os alunos levavam para a escola o que "tinham em casa". No final da década de 1960, começou a ser fornecido leite para os alunos. Posteriormente, segundo narra o aluno Davi (2014), a escola havia estabelecido um acordo com uma marca de macarrão, para servi-lo durante a merenda. Porém, para que isso ocorresse, os pais precisavam comprar o mesmo macarrão para consumo em suas casas. Mais uma indicação de que havia parco apoio financeiro dos governantes e que a escola buscava ou usava essas alternativas para funcionar e atender os alunos matriculados.

Por meio das fontes, constatou-se que a Escola ficava distante das casas de parte dos alunos e que estes percorriam quilômetros para assistir às aulas. Mesmo com a distância de sua casa para a escola, o aluno Mario (2014) afirma que "amava ir à escola", pois brincava um pouco e quando estava lá se sentia livre dos trabalhos na lavoura que realizava com seus pais. Narrativa que aponta um significado dado para a escola por um filho de lavrador, em acordo com enunciado que começava a se firmar, segundo o qual "lugar de criança é na escola" e não no trabalho; mas naquela localidade estava ainda distante a perspectiva formativa e profissionalizante que já circulava no país sobre a função dessa instituição social.

\subsection{Professores e metodologia de ensino}

Neste item foram pinçados aspectos referentes às condições de trabalho, formação e seleção de professores e do ensino.

Recordando, em diferentes discursos, incluindo o oficial, o papel da escola e o dos professores indicavam a educação/instrução como condição para a formação das crianças para a vida em sociedade. Na Mensagem (MATO GROSSO, 1952) proferida pelo governador Fernando Corrêa da Costa à Assembleia Legislativa, observa-se a importância dada aos conhecimentos e ao ensino:

Porque ensinar, mesmo que sejam noções apenas dos programas de ensino implica ter conhecimentos que não se cifram sómente [sic] à leitura, à escrita e à contabilidade, mas de higiene, saúde, domínio da terra e dos assuntos sociais mais de interesse da coletividade em que atua o professor [...]. (MATO GROSSO, 1952, p. 26).

Nos anos iniciais de funcionamento da Escola, apenas uma professora lecionava, mas, nos anos seguintes, outros professores foram contratados para exercer a docência. Até 1963 não foram encontrados registros, nem narrativas, de que havia outros funcionários, como servente, porteiro e inspetor. Segundo a Primeira Professora (2014), a função de diretora foi ocupada por ela durante, pelo menos, a primeira década de funcionamento da Instituição sem, contudo, ter sido nomeada ou receber o salário condizente com o cargo de direção. A justificativa dada foi a de que "era a professora mais antiga". Sobre esse aspecto nenhum registro foi encontrado (nem o Diário Oficial das nomeações), referente ao período em que ela informa ter ocupado as 
funções de professora e de diretora. Prática distante do previsto na legislação, que estabelecia que para ser diretor de uma escola pública o professor deveria comprovar experiência na docência de pelo menos três anos, além de passar por concurso público (BRITO, 2001). A primeira professora da Instituição tinha formação primária e estudou as séries iniciais do ginásio, sem concluí-lo. Somente no final da década de 1960, como apontado, uma professora "formada" (normalista) assumiu oficialmente a função de diretora da Escola.

A Professora Maria (2015), primeira normalista da cidade, assumiu aulas e a direção do Grupo Escolar na segunda metade da década de 1960 e permaneceu no cargo até 1969, quando passou a dirigir o Ginásio Estadual de Batayporã ${ }^{22}$. Segundo narrativas, logo após a criação do Ginásio, seis professores habilitados, vindos da cidade paulista de Alvares Machado em São Paulo, foram para Batayporã dar aulas, convidados pelo prefeito da cidade.

Com os dados das entrevistas e de outros registros disponíveis, observou-se que os professores raramente participavam de cursos ou aperfeiçoamentos oferecidos pelo governo do Estado nas cidades de Campo Grande e Cuiabá. Um dos principais motivos era a desobrigação da referida formação e a distância de Batayporã das cidades onde as capacitações eram oferecidas.

Em relação ao pagamento dos profissionais do Grupo, a primeira professora narra que, durante os anos que trabalhou, quando precisava receber o salário era "outro problema", pois não havia estrada entre Batayporã (distrito) e Bataguassu (município) onde costumava ir receber, pois para chegar até lá tinha que ir "beirando" as fazendas e que, em dias chuvosos, era mais difícil chegar ao destino. Afirma também que, em decorrência da distância, ficava "até cinco meses sem receber" (PRIMEIRA PROFESSORA, 2014).

Quanto ao ensino, recorrentes obstáculos foram encontrados para a educação dos alunos, pois, como nos primeiros anos eram salas multisseriadas, havia crianças iniciando a alfabetização e outras já dominando a escrita e a leitura. ${ }^{23}$ A principal referência para o ensino era a cartilha Caminho Suave. A própria professora a comprava para uso dos alunos, evidenciando a inexistência de indicação e gratuidade de uma cartilha específica por parte do poder público do Estado, como também a exigência de seguir uma cartilha específica. Segundo a professora, havia trabalhado com essa cartilha antes de ir para Batayporã, portanto, a escolha dela seguia a sua própria alfabetização e escolarização.

A cartilha Caminho Suave teve sua primeira publicação em 1948 e foi amplamente utilizada e aceita no país até meados de 1990. Segundo Peres e Ramil (2015), ela consistia em alfabetizar os alunos a partir das imagens impressas. Conforme os autores, a cartilha relacionava

a forma das tipografias das letras ou sílabas das palavras ao formato de sua respectiva imagem contribui para a memorização da criança, que associa as formas das fontes da tipografia utilizada na palavra às da imagem representada, pois os caracteres ocupam praticamente o mesmo espaço e assumem formato muito parecido, ao encaixar-se dentro de um detalhe da figura. (PERES; RAMIL, 2015, p. 63).

Além da cartilha, a professora utilizava o ditado, para o ensino da escrita. O acréscimo de conteúdos e atividades aparece somente no final dos anos de 1960. A Ficha do Estabelecimento, Boletim de Produção e Dados (GRUPO ESCOLAR, 2015a), sobre os alunos,

\footnotetext{
${ }^{22}$ O Ginásio, criado em 1969, funcionou com administração e prédio independentes do Grupo. Somente após a reforma educacional de 1971 foram integrados, com a criação da Escola Estadual de 1 Grau "Jan Antonin Bata" (MATO GROSSO, 1974).

${ }^{23}$ As salas multisseriadas, conforme Cardoso e Jacomeli (2010), eram salas únicas, sem separação, que abrigavam alunos de diversas séries, geralmente da primeira a quarta série e sob a regência de um único professor.
} 
contém informações de que em 1967, nos meses de março e abril, foram realizadas, respectivamente, quatro aulas de canto e uma de sabatina.

A distribuição espaço-temporal, o cuidado com a higiene e o comportamento, os exercícios morais, as orações diárias, as escriturações sobre o comportamento e outras práticas que se desenvolviam na Instituição estudada acabaram por compor e conformar os sujeitos.

Segundo Foucault (2004), a escola, como uma instituição social "fechada", é um lugar mantido pela ordem disciplinar que visa a adestrar o corpo e a mente pela obediência, docilidade e produtividade para o trabalho e a vida em sociedade.

$\mathrm{Na}$ escassa escrituração escolar localizada, que trata das notas dos alunos, percebe-se que havia um número expressivo de "notas baixas", principalmente no item chamado "Aplicação". As notas de Aplicação eram a soma das notas de comportamento e as notas das matérias lecionadas pelos professores; com a qual era realizada a média aritmética. Analisando os dados, concluiu-se que alguns alunos não iam bem, pois não se "comportavam" conforme as regras estabelecidas. Em um dos depoimentos dos alunos, contudo, pode-se localizar uma forma de resistência a esse disciplinamento e controle presentes na Instituição:

às vezes, de você querer ir ao banheiro e aqui, por exemplo, não tinha banheiro dentro da escola, era aquelas casinhas né de sítio mesmo, porque aqui era como se fosse um sítio né, e a gente as vezes queria sair, dar uma voltinha fora do recreio e não tinha como, você não podia sair, você tinha o recreio e tal e as vezes quando você estava muito apertado, então a gente fazia. E uma das travessuras que eu cansei de fazer, eu pegava giz e cortava com a gilete e fazia uns comprimidinhos assim [gesto de pequeno com as mãos] né, e falava professora, preciso tomar meu remédio. Então vai [a professora dizia], e aí eu ia lá, tomava uma água, ficava por ali e voltava como se estivesse com cara de doente e tal. (ALUNO DAVI, 2014, p. 5).

Dialogando com Foucault (2013), pode-se refletir que a "posição de sujeito" ocupada pela professora (e outros professores) lhe garantia ou exigia certa autonomia no exercício de sua função como "educadora"; posição que implicava o controle de seus alunos, em especial ou se necessário, pela disciplina. Mas, é preciso problematizar essa conduta dos professores, visto que eles mesmos eram submetidos a determinadas regras, se não do departamento de educação ou da inspeção escolar, mas de seus próprios colegas, quando estes ocupavam a posição de chefia, como diretor ou, ainda, pelo controle da própria conduta. Nesse sentido, a Ficha do Estabelecimento - Boletim de Produção e Dados (GRUPO ESCOLAR, 2015a) permite observar o tipo de informações requeridas aos professores ao ministrar aulas no Grupo Escolar que, além da formação acadêmica, se dirigiam ao estado civil, à experiência e às atividades realizadas em sala de aula.

Há também na escrituração escolar registros detalhados sobre os alunos, como data de matrícula, peso, altura, idade, naturalidade, sexo, série, de que escola vieram (escola particular ou pública); registros que faziam parte das atribuições da escola; além de dados dos familiares, como profissão, religião, escolaridade e outros. Detalhamento que permite evidenciar que, por meio de diferentes registros e medidas, estavam "todos" os sujeitos capturados nessa escritura escolar.

Por mais de uma década, em Batayporã, ao terminar a $4^{\mathrm{a}}$ série, os alunos deixavam de estudar, caso seus pais não tivessem condições financeiras de enviá-los para estudar em Bataguassu (cidade mais próxima) ou em outra cidade, condição da maioria dos moradores; situação que aparece nas narrativas dos alunos sobre a década de 1960, momento em que as primeiras crianças haviam concluído o curso primário. 


\subsection{Educar e instruir para a vida em sociedade: moral e civismo na Escola}

Neste tópico foi analisada a responsabilização dos professores para com a formação moral e cívica das crianças, por meio de discursos e práticas que se efetivavam na Escola e nas atividades comemorativas da pequena cidade. Tarefa que implicava a existência de professores "cheios de virtudes", que serviam de modelo a ser seguido, exemplos de "cidadãos que trabalhavam pela pátria". Aspecto reforçado na Mensagem (MATO GROSSO, 1952) do governador Fernando Corrêa da Costa, citada anteriormente.

$\mathrm{Na}$ chegada à Escola, diariamente, os alunos eram recebidos com um momento de "acolhida", no qual cantavam o Hino Nacional e hasteavam a Bandeira do Brasil, bem como faziam oração pelo dia que estava começando. Depois da acolhida, eles eram levados para a sala de aula para as atividades pedagógicas.

O recreio não era livre, mas controlado por meio de atividades dirigidas, recreativas ou não, que exploravam outras formas de cuidado sobre o corpo das crianças e dos adolescentes que estudavam naquela escola. Dirigindo o olhar para os alunos, pode-se perguntar como agiam, resistiam e lidavam com certo cerceamento espaço-temporal.

Nas entrevistas com a professora do Grupo e alunos, esses aspectos aparecem em algumas passagens, nas quais afirmam a frequente realização de festividades cívicas, comemorando, por exemplo, o Dia da Bandeira; momentos em que se realizavam desfiles com batalhões infantis marchando e tocando um instrumento diante das autoridades que estavam presentes nos desfiles oficiais (imagem que ainda nos é familiar). Professores e alunos entrevistados demonstram entusiasmo e orgulho de terem participado dessas práticas, desses ritos, porque se estava "homenageando um fato histórico do Brasil".

Nesse sentido, essas atividades, consideradas extraclasses, contribuíam para a formação das crianças e dos adolescentes matriculados na Instituição, ou, com apoio de Rose (2001), para compor e conformar subjetividades infantis, nesse caso, patriotas. Com as entrevistas realizadas, além de fotos encontradas no Centro de Memória "Jindrich Trachta", foi observada a presença desses atos que ocorriam na Escola, desde a acolhida diária com a execução do Hino Nacional e hasteamento da Bandeira do Brasil, até as comemorações do Dia de Tiradentes e de 7 de Setembro, por exemplo. Em duas imagens identificadas como sendo de 1955, aparecem os meninos e as meninas (separadamente) uniformizados, indicando a participação da Escola em evento oficial da cidade.

Figura 2. Alunas durante a $1^{\text {a }}$ Festividade Cívica em Batayporã (1955)

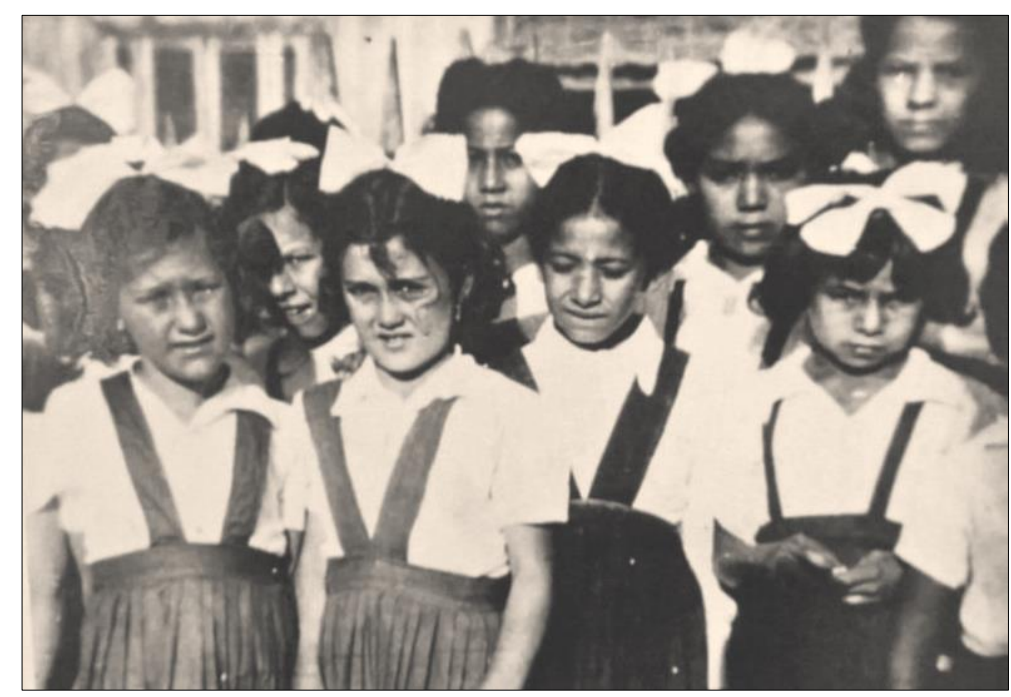

Fonte: Centro de Memória “Jindrich Trachta” (2015). 
Não obtivemos informações que permitissem afirmar se o uniforme era utilizado somente em dias "especiais" ou nas "datas comemorativas", mas é possível afirmar que nesses dias eles o usavam. Essas datas, além de vitrine dos feitos da escola, segundo as narrativas dos sujeitos entrevistados, explicitam que havia contatos políticos entre funcionários e governantes, para contratação e indicação de funções dentro da escola ou da educação em geral.

Dessa formação aparentemente "complementar" é possível inferir que a escola e os professores eram responsáveis, além de outros inúmeros aspectos, pela constituição do imaginário e da memória nacional, instruindo a si mesmos e aos seus alunos em valores como o respeito aos signos e símbolos da Pátria.

Dialogando com a produção de outros autores sobre a temática, Vidal (2006, p. 9) evidencia que os grupos escolares "fundaram uma representação de ensino primário que não apenas regulou o comportamento, [...], de professores e alunos no interior das instituições escolares, como disseminou valores e normas sociais (e educacionais)".

Além de consolidar e reforçar nas crianças exemplos de "heróis patrióticos" a serem seguidos, por terem lutado em prol do país, essas práticas implicavam, ao mesmo tempo, a tentativa de constituição de cidadãos dóceis, disciplinados, aptos a viverem em sociedade e condizentes com os interesses da República:

a escola pública tornou-se palco de realização das comemorações cívicas, mais um dentre os traços inequívocos de aliança da escola primária com a República e com os valores cívico-patrióticos. Tais festas tinham como objetivo solenizar algumas datas "notáveis" da nossa história. (SOUZA, 1998, p. 265).

Conforme Souza (1998, p. 241), pode-se afirmar que:

A escola republicana instaurou ritos, espetáculos, celebrações. Em nenhuma outra época, a escola primária, no Brasil, mostrara-se tão francamente como expressão de um regime político. De fato, ela passou a celebrar a liturgia política da República; além de divulgar a ação republicana, corporificou os símbolos, os valores e a pedagogia moral e cívica que lhe era própria. Festas, exposições escolares, desfiles dos batalhões infantis, exames e comemorações cívicas constituíram momentos especiais na vida da escola pelos quais ela ganhava ainda maior visibilidade social e reforçava sentidos culturais compartilhados.

Observa-se certo "governamento" dos corpos das crianças e dos adolescentes, correlato da noção de "instituição". Inscritos nessas relações de poder ou de governo do outro, presentes na relação professor-alunos, havia também os espaços de resistências ou de "liberdade" controlada:

Embora a vigilância possa não ocorrer a todo instante, ela é sentida permanentemente. $\mathrm{O}$ indivíduo constantemente vigiado aprende a vigiar a si mesmo, internaliza as relações de poder, aprende a disciplinar seu corpo e sua forma de vida, tornando-se, assim, o seu próprio guardião. (MORAES, 2008, p. 61-62).

O Grupo Escolar de Batayporã configurou-se como um ambiente de preservação e cultivo de valores cívicos e patrióticos, contribuindo em certa medida para a constituição de subjetividades infantis "educadas" de um modo específico. 


\section{Considerações finais}

O artigo socializa resultados sobre a institucionalização da educação na cidade de Batayporã, no sul do antigo Mato Grosso, hoje, Mato Grosso do Sul, materializada na existência de um grupo escolar, que apareceu em 1955, inserida em um projeto de colonização, no momento em que a localidade era distrito e, portanto, ainda não havia alcançado sua emancipação político-administrativa.

Com o apoio de noções foucaultianas, o processo de escolarização que se desenrolou no interior da instituição educacional de Batayporã foi tratado como um dispositivo, que, de modo semelhante a outras instituições sociais, pelas suas práticas, rituais, simbolismos, coloca os corpos dos sujeitos como objeto de poderes e de saberes específicos.

Considerando os resultados apontados, pelo contato com os sujeitos singulares que fizeram parte da história da Instituição e com as fontes documentais e fotográficas analisadas, pode-se considerar que a Instituição estudada, em sua materialidade, contribuiu para a fixação dos migrantes e imigrantes naquele local e momento histórico e que esse acontecimento não ficou no passado, pois permanece sendo elemento que compõe as lembranças da história do lugar e das pessoas que a consolidaram.

Tentativas de manter vivos esses acontecimentos em suas lembranças são expressas pela criação do Centro de Memória "Jindrich Trachta" em Batayporã ou no resgate e guarda de alguns dos documentos que registram os feitos da escola nos primeiros anos de sua existência material, quando poderiam legalmente tê-los incinerados.

Mesmo parecendo-se com outras instituições escolares que funcionaram naquele período, interessou indagar suas particularidades em meio às tentativas homogeneizadoras das políticas, da legislação, das nomenclaturas e das ordens estabelecidas.

A pesquisa realizada e o conhecimento dela resultante não esgotam as possibilidades de outras investigações mais específicas, pois a aproximação dos discursos e práticas que constituíram a Instituição estudada não se esgotaram; a tarefa de historicizá-la permanece.

\section{Referências}

ALBUQUERQUE JÚNIOR, Durval Muniz de. A história em jogo: a atuação de Michel Foucault no campo da historiografia. In: de teoria da história. Bauru: EDUSC, 2007. . História: a arte de inventar o passado: ensaios

ALUNO DAVI. Entrevista. Batayporã, MS, 28 nov. 2014. 8 f.

BRASIL. Constituição dos Estados Unidos do Brasil, de 18 de setembro de 1946. Rio de Janeiro, 1946. Disponível em: http://www.planalto.gov.br/ccivil_03/Constituicao/ Constituicao46.htm. Acesso em: 30 mar. 2015.

BRASIL. Lei $n^{\circ}$ 4.024, de 20 de dezembro de 1961. Fixa as Diretrizes e Bases da Educação Nacional. Brasília, DF, 1961. Disponível em: https://www.planalto.gov.br/ccivil_03/ Leis/L4024.htm. Acesso em: 25 maio 2014.

BRASIL. Lei $n^{\circ} 5.692$, de 11 de agosto de 1971. Fixa as diretrizes e bases para o ensino de $1^{\circ}$ e $2^{\circ}$ graus, e dá outras providências. Brasília, DF, 1971. Disponível em: <https://www.planalto.gov.br/ccivil_03/Leis/L5692.htm>. Acesso em: 25 jun. 2014. 
BRASIL. Lei Complementar $n^{\circ}$ 31, de 11 de outubro de 1977. Cria o Estado de Mato Grosso do Sul, e dá outras providências. Brasília, DF, 1977. Disponível em: $<$ http://presrepublica.jusbrasil.com.br/legislacao/103663/lei-complementar-31-77>. Acesso em: 20 dez. 2015.

BRASIL. Lei $n^{\circ} 601$, de 18 de setembro de 1850. Dispõe sobre as terras devolutas do Império. Rio de Janeiro, 1850. Disponível em: <http://www.planalto.gov.br/ccivil_03/Leis/L06011850.htm>. Acesso: 20 jun. 2015.

BRITO, Silvia. Educação e sociedade na fronteira Oeste do Brasil: Corumbá (1930-1954). 2001. 372 f. Tese (Doutorado em Educação) - Universidade Estadual de Campinas, Campinas, SP, 2001.

BUFFA, Ester; PINTO, Gerson Almeida. Arquitetura e educação: organização do espaço e propostas pedagógicas dos grupos escolares paulistas (1893-1971). São Carlos: EDUFSCar/INEP, 2002.

CARDOSO, Maria Angélica; JACOMELI, Maria Regina Martins. Considerações sobre as escolas multisseriadas: estado da arte. Educere et Educare, Cascavel, v. 5, n. 9, p. 267-290, 2010.

CENTRO DE MEMÓRIA “JINDRICH TRACHTA”. Prédio do Grupo Escolar de Bataiporã, fundos (1957). Acervo. Batayporã-MS, 2015.

CENTRO DE MEMÓRIA “JINDRICH TRACHTA". Alunas durante a primeira Festividade Cívica em Bataiporã (1955). Acervo. Batayporã-MS, 2015.

ESCOLA RURAL MISTA DE BATAIPORÃ. Livro de chamada de aluno: Bataiporã, MT, 1962. Batayporã, MS: Arquivo da Escola Estadual "Jan Antonin Bata", 2015.

FARIA FILHO, Luciano Mendes de; VIDAL, Diana Gonçalves. Os tempos e os espaços escolares no processo de institucionalização da escola primária no Brasil. Revista Brasileira de Educação, Rio de Janeiro, v. 14, n. 14, p. 19-34, 2000.

FOUCAULT, Michel. A ordem do discurso: aula inaugural do Collège de France, pronunciada em 2 de dezembro de 1970. Tradução Laura Fraga de Almeida Sampaio. 23. ed. São Paulo: Edições Loyola, 2013.

FOUCAULT, Michel. Vigiar e punir: história da violência nas prisões. Tradução Raquel Ramalhete. 29. ed. Petrópolis: Vozes, 2004.

FRAGO, Antônio Viñao; ESCOLANO, Augustín. Currículo, espaço e subjetividade: a arquitetura como programa. Tradução Alfredo Veiga-Neto. 2. ed. Rio de Janeiro: DP\&A, 2001.

FREITAS, Marcos Cezar de; BICCAS, Maurilene de Souza. História social da educação no Brasil (1926-1996). São Paulo: Cortez, 2009. (Biblioteca básica da história da educação brasileira, v.3).

GALETTI, Lylia da Silva Guedes. Sertão, Fronteira, Brasil: imagens de Mato Grosso no mapa da civilização. Cuiabá: EdUFMT/Entrelinhas, 2012.

GARNICA, Antônio Vicente Marafioti. Memórias de uma escola isolada rural: estudo de um livro de visitas (1928-1948). Revista Educação Social, Campinas, v.32, n.114, p. 69-86, 2011. https://doi.org/10.1590/S0101-73302011000100005 
GRUPO ESCOLAR DE BATAYPORÃ. Ficha do estabelecimento, boletim de produção e dados. Bataiporã, MT (1967). Batayporã: Arquivo da Escola Estadual "Jan Antonin Bata", $2015 \mathrm{a}$.

GRUPO ESCOLAR DE BATAYPORÃ. Livro de matrícula, frequência diária e aparelhamento escolar. Bataiporã, MT, 1957-1962. Batayporã, MS: Arquivo da Escola Estadual "Jan Antonin Bata", abr. 2015 b.

GUILLEN, Isabel Cristina Martins. O lugar da história: confronto e poder em Mato Grosso do Sul. Revista Cientifica, Campo Grande: UFMS, v. 3, n. 2, p. 37-44, 1996.

IBGE-Instituto Brasileiro de Geografia e Estatística. Enciclopédia dos municípios brasileiros. Brasília: IBGE/PNAD, 1958.

IGNACIO, Paulo César de Souza. Leis orgânicas do ensino (1942-1946). In: HISTEDBR. Glossário. 2006. Disponível em: <http://www.histedbr.fe.unicamp.br/navegando/glossario/ verb_c_leis_organicas_do_ensino.htm>. Acesso em: 12 abr. 2017.

JORNAL ORDEM E PROGRESSO. Indiana/SP, 1942. In: ZILIANI, J. C. Colonização: táticas e estratégias da Companhia de Viação São Paulo-Mato Grosso (1900-1960). 2010. 244 f. Tese (Doutorado em História) - Universidade Estadual Paulista, Assis, SP, 2010.

LIMA, Solange Ferraz de; CARVALHO, Vania Carneiro de. Usos sociais e historiográficos. In: PINSKY, Carla Bassanezi; LUCA, Tania Regina de (Orgs.). O historiador e suas fontes. São Paulo: Contexto, 2009. p. 29-60.

MATO GROSSO. Carta de Hermes Rodrigues de Alcântara ao governador do estado de Mato Grosso Fernando Corrêa da Costa. In: MATO GROSSO. Programa do Ensino Primário. Cuiabá: Imprensa Oficial do Estado de Mato Grosso/Arquivo Público de Mato Grosso, 1962a.

MATO GROSSO. Decreto ${ }^{\circ} 1.850$, de 31 de janeiro de 1974. Dispõe sobre a integração física das escolas que menciona, no município de Bataiporã e traz outras providências. Diário Oficial [do] Estado de Mato Grosso, Bataiporã, MS: Arquivo da Escola Estadual "Jan Antonin Bata", n. 16.526, 5 fev. 1974.

MATO GROSSO. Decreto $n^{\circ} 2.066$, de 04 de março de 1955. Dispõe sobre a criação do Grupo Escolar de Bataiporã. Batayporã, MS: Arquivo da Escola Estadual "Jan Antonin Bata”, 2015.

MATO GROSSO. Decreto $n^{o}$ 319, de 1962. Programa do Ensino Primário. Cuiabá, MT: Arquivo Público de Mato Grosso, 1962 b.

MATO GROSSO. Lei orgânica do ensino primário do Estado de Mato Grosso, Lei $\mathrm{n}^{\circ}$ 452, de 1951. In: BRITO, Sílvia Helena A. de. Educação e sociedade na fronteira Oeste do Brasil: Corumbá (1930-1954). 2001. 372 f. Tese (Doutorado em Educação) - Universidade Estadual de Campinas, Campinas, SP, 2001.

MATO GROSSO. Mensagem apresentada pelo Governador do Estado de Mato Grosso, Fernando Corrêa da Costa, por ocasião do início da legislatura de 1952. Cuiabá: Imprensa Oficial do Estado de Mato Grosso/Arquivo Público de Mato Grosso, 1952.

MATO GROSSO. Regulamento da instrução pública primária. Cuiabá, MT: Arquivo Público de Mato Grosso, 1927. 
MORAES, Antônio Luiz de. Disciplina e controle na escola: do aluno dócil ao aluno flexível. 2008. 148 f. Dissertação (Mestrado em Educação) - Universidade Luterana do Brasil, Canoas/RS, 2008.

PERES, Eliane Teresinha; RAMIL, Chris DE AZEVEDO. Alfabetização pela imagem: uma análise iconográfica da cartilha Caminho Suave e do material de apoio. Cadernos de Pesquisa em Educação, Vitória: PPGE/UFES, ano 12, n. 41, p. 53-79, 2015.

PREFEITURA MUNICIPAL DE BATAYPORÃ. Lei $n^{o}$ 3.372, de 17 de maio de 2007. Modifica a nomenclatura do município de Bataiporã, Mato Grosso do Sul. Batayporã: Prefeitura Municipal, 2007.

PRIMEIRA PROFESSORA. Entrevista. Batayporã, MS, 29 set. 2014. 18 f.

PROFESSORA MARIA. Entrevista. Batayporã, MS, jun. 2015. 10 f.

ROSE, Nikolas. Inventando nossos eus. In: SILVA, Tomaz Tadeu da. Nunca fomos humanos: nos rastros do sujeito. Tradução Tomaz Tadeu da Silva. Belo Horizonte: Autêntica, 2001.

SCHWARCZ, Lilia Moritz. O espetáculo das raças: cientistas, instituições e questão racial no Brasil: 1870-1930. São Paulo: Companhia das Letras, 2014.

SOUZA, Rosa Fátima de. Fotografias escolares: a leitura de imagens na história da escola primária. Educar, Curitiba: Editora da UFPR, n.18, p.75-101, 2001. https://doi.org/10.1590/0104-4060.235

SOUZA, Rosa Fátima de. Templos de civilização: a implantação da escola primária graduada no Estado de São Paulo (1890-1910). São Paulo: UNESP, 1998.

VIDAL, Diana Gonçalves. Tecendo história (e recriando memória) da escola primária e da infância no Brasil: os grupos escolares em foco. In: (Org.). Grupos escolares: cultura escolar primária e escolarização da infância no Brasil (1893-1971). Campinas: Mercado das Letras, 2006.

ZILIANI, José Carlos. Colonização: táticas e estratégias da Companhia de Viação São Paulo Mato Grosso (1900-1960). 2010. 244 f. Tese (Doutorado em História) - Universidade Estadual Paulista, Assis, SP: UNESP, 2010. 